\title{
Association between Parathyroid Hormone and Anemia: A Cross-Sectional Observational Study of maintenance Hemodialysis Patients of a Tertiary Care Center
}

\section{Abdul Mannan Junejo, Muhammad Ali, Shafique Ahmed, Ayesha Ejaz, Hina Iram, Sandeep Kumar.}

Department of Nephrology, Jinnah Postgraduate Medical Center Karachi, Pakistan.

\author{
Abstract \\ Objective \\ The objective of this study was to assess the relationship between intact parathyroid hormone levels (iPTH) and hemoglobin (Hb) levels in patients with \\ end-stage renal disease (ESRD) who were on hemodialysis. \\ Material and methods \\ An observational, cross-sectional study was conducted in the Department of Nephrology at Jinnah Postgraduate Medical Centre in Karachi, Pakistan. \\ Patients were enrolled in this study after consent and institutional review board approval. Serum samples were collected for Hb level, iPTH level, vitamin \\ $\mathrm{D}$, urea and creatinine, ferritin, and transferrin saturation. \\ Results \\ Ninety four patients were inducted into this study; men comprised $66.0 \%$ of the patients, and Diabetes mellitus was the commonest etiology of ESRD. \\ Most of the patients were on dialysis for more than 5 years on twice per week hemodialysis. Mean Hemoglobin was 9.29g/dl, iPTH 576.59ng/dl and \\ Vitamin D 25.47ng/ml. Significant inverse correlation was found between anemia and i-PTH levels. \\ Conclusion \\ Hyperparathyroidism is one of the major contributor anemia among maintenance hemodialysis patients.
}

Keywords: anemia, chronic kidney disease, erythropoietin, hyperparathyroidism, hemodialysis, End stage renal disease, mineral bone disease.

\section{Corresponding Author}

Department of Nephrology,

Jinnah Postgraduate Medical Center,

Karachi, Pakistan.

Email Address: dramanan99@gmail.com

\section{Introduction}

Anemia is one of the main consequences of long-term renal disease, especially in patients receiving treatment in the form of hemodialysis. The primary reason for the development of anemia in patients with end stage renal disease (ESRD) is the decreased production of erythropoietin (EPO); however, the cause is multifactorial. ${ }^{2}$

The primary treatment for correction of anemia secondary to renal insufficiency is the use of recombinant EPO. ${ }^{3}$ This, in turn, increases the financial cost of treatment multifold. ${ }^{4}$ Many studies revealed that iron deficiency, infections, inflammation, and chronic blood loss are the main reasons for the inability of erythropoietin to correct the secondary anemia in patients with ESRD. ${ }^{5-8}$ Concomitant occurrence of secondary hyperparathyroidism in patients with ESRD is another important factor. ${ }^{9}$ This is another significant consequence of ESRD, secondary to phosphate retention, hypocalcemia, and reduced levels of calcitriol - the active form of vitamin D. ${ }^{10}$ Parathyroid glands are located behind the thyroid gland. They constitute a part of the body's endocrine system and are mainly responsible for the regulation of calcium, parathyroidectomy proven beneficial in improving hemoglobulin and decrease demand of EPO. ${ }^{1}$

Parathyroid hormone has been considered a uremic toxin that can potentially inhibit EPO synthesis, cause myelofibrosis, and shorten red blood cell survival, which eventually decreases hematopoiesis. ${ }^{11}$ Only a few studies have been conducted to study the association between parathyroid hormone and anemia in patients with ESRD undergoing hemodialysis. Studies in Italy in 2011, and Turkey in 2018 explored these correlations; however, the results have not been consistent. ${ }^{910}$

Fibroblast growth factor 23 (FGF 23) another hormone secreted from bones may also be involved in influencing erythropoiesis in CKD. ${ }^{12}$ Hence, this study was conducted with the aim to assess the relation of intact parathyroid hormone levels (i-PTH) and hemoglobin (Hb) levels in ESRD patients on hemodialysis. 


\section{I-PTH \& Anemia in ESRD}

\section{Materials and Methods}

We conducted an observational, cross-sectional study in the Department of Nephrology at Jinnah Postgraduate Medical Centre in Karachi, Pakistan. Ethical approval was obtained from the institutional review board.

We included all patients above age of 18 years actively on maintenance hemodialysis and receiving EPO. EPO dose was adjusted as per the target hemoglobin between 10-11.5 g/dl.

All the patients having active malignancy, hematologic disorders, active infection and documented pure red cell aplasia were excluded from the study.

Patients' gender, age, marital status, ethnicity, comorbidities, significant family history, history of smoking or substance abuse, and other related data were recorded. Serum samples were collected pre-dialysis first hemodialysis session of the week for hemoglobin level, serum i-PTH level, vitamin D, urea and creatinine, ferritin, and transferrin saturation. All were recorded in a predefined proforma.

\section{Statistical analysis}

Data were analyzed using IBM SPSS Statistics for Windows, Version 24.0. (Armonk, NY: IBM Corp.). The age of patients and other continuous variables were presented as mean and standard deviation. Cut off point for $\mathrm{Hb}$ was set as $10 \mathrm{mg} / \mathrm{dL}$, an independent $\mathrm{t}$-test and Pearson correlation was used to assess the primary outcome of hemoglobin versus parathyroid hormone was applied for comparison between the study and control groups..$^{13}$ The chi-square test was used to compare variables. A p-value of $<0.05$ was considered to be statistically significant.

\section{Results}

In our study comprising of 94 patients, 62 (66\%) were men and $32(34 \%)$ were women. The laboratory values are presented in Table 1. Etiology of ESRD was found to diabetic nephropathy in majority of patients followed by hypertension, Table 2.

Table: 1 Clinical characteristic of patients in the study population

\begin{tabular}{|l|l|l|}
\hline Variables & Mean & Std. Deviation \\
\hline Vit-D & 22.43 & \pm 11.98 \\
\hline Iron & 100.01 & \pm 73.69 \\
\hline T-Stat & 37.85 & \pm 16.69 \\
\hline Calcium & 8.11 & \pm .82 \\
\hline Phosphate & 5.67 & \pm 1.70 \\
\hline Creatinine & 7.95 & \pm 2.50 \\
\hline Albumen & 3.33 & \pm .538 \\
\hline Duration of dialysis (years) & 4.09 & \pm 1.14 \\
\hline Session/week & 1.54 & \pm .50 \\
\hline Hemoglobin & 9.02 & \pm 1.32 \\
\hline i-PTH* & 646.22 & \pm 587.42 \\
\hline Ferritin & 592.92 & \pm 399.78 \\
\hline Uric Acid & 8.16 & \pm 15.41 \\
\hline Age & 45.2 & \pm 12.6 \\
\hline *iPTH, intact parathyroid hormone; TSAT: Transferrin saturation
\end{tabular}

Table: 2 cause of End stage renal disease of patients in the study population

\begin{tabular}{|l|l|l|}
\hline Cause & Frequency & Percentage \\
\hline Hypertension & 16 & 17.0 \\
\hline Pregnancy related cause & 3 & 3.2 \\
\hline Bilateral Small Size Kidneys & 10 & 10.6 \\
\hline Chronic Glomerulonephritis & 10 & 10.6 \\
\hline Contrast Induced Nephropathy & 2 & 2.1 \\
\hline Diabetes Mellitus & 45 & 47.9 \\
\hline Renal Stone & 6 & 6.4 \\
\hline Myeloma & 2 & 2.1 \\
\hline
\end{tabular}

In our study most of the patients were undergoing hemodialysis twice per week in $54.3 \%$ of patients and almost half of them were on hemodialysis for more than 5 years $51.1 \%$.

Anemia was more common among women with a mean serum $\mathrm{Hb}$ of $9.48 \pm 1.4 \mathrm{~g} / \mathrm{dL}$ vs. $10.03 \pm 1.2 \mathrm{~g} / \mathrm{dL}$ among men, respectively. Similarly the mean iPTH was 662.46 among women, which was higher than in men, $554.05 \mathrm{pg} / \mathrm{dL}$. Anemia and hyperparathyroidism were found to be more severe in patients of ESRD due to hypertension and Diabetes mellitus, Table 3. Pearson correlation analysis revealed a significant correlation between i-PTH and Hb levels, Figure 1, Table 4. 
Table 3: Correlation of hemoglobin and i-PTH levels with etiology of end stage renal disease among 94 maintenance hemodialysis patients.

\begin{tabular}{|l|c|c|c|}
\hline Cause & i-PTH ng/dl & Hemoglobin g/dl & \\
\cline { 1 - 2 } Hypertension & $794.45 \pm 752.15$ & $8.38 \pm 1.29$ & \\
\hline Pregnancy related cause & $602.06 \pm 540.04$ & $9.73 \pm 1.53$ & \multirow{3}{*}{ Over all P value $=0.0001$} \\
\cline { 1 - 2 } Bilateral Small Size Kidneys & $613.90 \pm 712.98$ & $9.11 \pm 1.51$ & \\
\hline Chronic GN & $546.30 \pm 309.58$ & $8.78 \pm 1.10$ & \\
\hline Contrast Induced Nephropathy & $452.75 \pm 90.15$ & $9.70 \pm 1.27$ & \\
\cline { 1 - 2 } Diabetes Mellitus & $538.07 \pm 593.10$ & $9.58 \pm 1.33$ & \\
\cline { 1 - 2 } Renal Stone & $428.51 \pm 297.35$ & $9.81 \pm 1.55$ & \\
\cline { 1 - 2 } Multiple Myeloma & $195.30 \pm 96.73$ & $10.90 \pm .98$ & \\
\hline
\end{tabular}

Figure 1: Co-relation of Hemoglobin and i-PTH levels among 94 maintenance hemodialysis patients.



\section{Discussion}

Our study clearly highlights the presence of secondary hyperparathyroidism as a factor for persistent anemia in patients on maintenance hemodialysis on continuous EPO treatment. Anemia in hemodialysis patients increases mortality and morbidity, leading to poor outcomes and a poor prognosis, though mainly attributed to a deficiency of erythropoietin due to either a reduction in production or resistance of erythropoietin in the body. ${ }^{1,12}$ Another factor hyperparathyroidism, by causing fibrosis of the bone marrow leads to anemia other factors commonly encountered are elevated FGF23 levels and iron deficiency. ${ }^{9-16}$

Table 4: Analysis of Significant correlation of mean hemoglobin with different variables.

\begin{tabular}{|l|l|l|l|l|}
\hline Variables & $\mathrm{t}$ & $\mathrm{df}$ & Sig. (2-tailed) & Mean Difference \\
\hline PTH & -8.214 & 91.99 & 0.00 & -559.64 \\
\hline Creatinine & .420 & 11.25 & 0.68 & 0.35 \\
\hline Cause & 2.028 & 11.95 & 0.06 & 1.26 \\
\hline Duration of hemodialysis (years) & -2.988 & 10.26 & 0.01 & -1.33 \\
\hline Session-week & -.927 & 11.10 & 0.37 & -0.159 \\
\hline Phosphate & -.546 & 14.27 & 0.59 & -0.23 \\
\hline Calcium & -1.088 & 14.79 & 0.29 & -0.21 \\
\hline Albumen & -.815 & 13.30 & 0.43 & -.12 \\
\hline Vit-D & .053 & 10.08 & 0.96 & 0.28 \\
\hline Iron & -.579 & 15.30 & 0.57 & -9.90 \\
\hline Ferritin & -1.441 & 21.10 & 0.16 & -109.58 \\
\hline
\end{tabular}

Our patients clearly had hyperparathyroidism while the iron status was adequate. EPO resistance is defined as a persistent anemia (hemoglobin $<10-12 \mathrm{~g} / \mathrm{dL}$ ) or the necessity of very high erythropoietin doses of epoetin alfa (300 IU/kg/week subcutaneously or $450 \mathrm{IU} / \mathrm{kg} /$ week intravenously). ${ }^{17}$ None of our patients were on dosage of EPO suggestive of EPO resistance. In a recent study by Anees et.al. from Lahore Pakistan anemia was common (68.5\%) with adequate iron stores. ${ }^{18}$ They speculated that inadequate dialysis and dosage of EPO as the main cause of anemia. In yet another study by Rizvi et.al. high turnover bone disease was common among 61 maintenance dialysis patients although they did not mention the anemia prevalence their population. ${ }^{19}$ Another study from Karachi, Pakistan revealed similar occurrence of high prevalence of hyperparathyroidism and anemia, although no correlation were done to assess the significance of 


\section{I-PTH \& Anemia in ESRD}

effect. ${ }^{20}$ Our study therefore bridges these gaps present in the local literature and clearly shows a correlation among hyperparathyroidism and anemia prevalence in maintenance hemodialysis patients. Our results were also similar to reported internationally. ${ }^{21.55}$

Recently Asif et.al have raised an interesting hypothesis in terms of management of secondary hyperparathyroidism with vitamin D supplementation among maintenance dialysis patients without any adverse effects. ${ }^{26}$ Mean vitamin D level among our patients were quite low, $23.5 \mathrm{ng} / \mathrm{mL}$. It will be interesting to see if management with vitamin D supplementation for secondary hyperparathyroidism will result in improvement in anemia status and possibly decrease in the EPO use. A study is therefore needed to look into this aspect of management among maintenance hemodialysis patients with anemia and secondary hyperparathyroidism.

\section{Conclusions}

Anemia in ESRD patients is multifactorial the most common being erythropoietin and iron deficiency. Our study clearly highlights the presence of hyperparathyroidism as a significant cause of anemia, likely due to the resistance to the action of EPO. Strict monitoring and strict control of hyperparathyroidism to prevent EPO resistant and anemia is needed.

\section{Conflict of Interest None Declared References}

1. Gafter-Gvili A, Schechter A, Rozen-Zvi B: Iron deficiency anemia in chronic kidney disease. Acta Haematol. 2019, 142:44-50.

2. Bal Z, Demirci BG, Karakose S, Tutal E, Uyar ME, Acar NO et al.: Factors influencing hemoglobin variability and its association with mortality in hemodialysis patients. Sci World J. 2018, 2018:8065691.

3. de Freitas JS, Costa PS, Costa LR, Naghettini AV: Evaluation of clinical and laboratory variables associated with anemia in pediatric patients on hemodialysis. J Pediatr (Rio J). 2015;91:87-92.

4. Fishbane S, Spinowitz B: Update on anemia in ESRD and earlier stages of CKD: core curriculum 2018. Am J Kidney Dis. 2018, 71:423-435.

5. Nafar M, Samavat S, Khoshdel A, Alipour-Abedi B: Anemia evaluation and erythropoietin dose requirement among hemodialysis patients. Iran J Kidney Dis. 2017, 11:56-65.

6. Gummer J, Trengove R, Pascoe EM, Badve SV, Cass A, Clarke P et al.: Association between serum hepcidin-25 and primary resistance to erythropoiesis-stimulating agents in chronic kidney disease: a secondary analysis of the HERO trial. Nephrology (Carlton). 2017, 22:548-554.

7. Kesztyüs T, Simonsmeier U, Kesztyüs D: Developing a classification system for haemoglobin management in patients with end-stage renal disease on haemodialysis: a secondary data analysis. BMJ Open. 2017, 7:e017423.

8. Fabrizi F, Donato FM, Messa P: Association between HBV virus \& CKD: a systematic review and meta-analysis. Ann Hepatol 2017,16:21-47.

9. Tanaka M, Komaba H, Fukagawa M: Emerging association between parathyroid hormone and anemia in hemodialysis patients. Ther Apher Dial. 2018, 22:242-245.

10. Arrangoiz R, Cordera F, Caba D, Muñoz M, Moreno E, Luque-de-León E: Parathyroid embryology, anatomy, and pathophysiology of primary hyperparathyroidism. Int J Otolaryngol Head Neck Surg. 2017, 6:39-58.

11. Hamano N, Komaba H, Fukagawa M: Effect of PTH on the hematologic system. In Parathyroid Glands in Chronic Kidney Disease. Covic A, Goldsmith D, Ureña Torres P (eds). Springer, Cham; 2020. 8:117-141.

12. Coe LM, Madathil SV, Casu C, Lanske B, Rivella S, Sitara D. FGF-23 is a negative regulator of prenatal and postnatal erythropoiesis. J Biol Chem 2014; 289:9795 - 810

13. Locatelli F, Bárány P, Covic A De Francisco A, Del Vecchio L, Goldsmith D et.al. ERA-EDTA ERBP Advisory Board. Kidney Disease: Improving Global Outcomes guidelines on anaemia management in chronic kidney disease: a European Renal Best Practice position statement. Nephrol Dial Transpl. 2013 Jun; 28(6):1346-59.

14. Panwar B, Gutiérrez OM: Disorders of iron metabolism and anemia in chronic kidney disease. Semin Nephrol. 2016, 36:252-261.

15. Kalantar-Zadeh K, Lee GH, Miller JE, Streja E, Jing J, Robertson JA et al. Predictors of hyporesponsiveness to erythropoiesis-stimulating agents in hemodialysis patients. Am J Kidney Dis 2009; 53:823 - 34

16. Rao DS, Shih MS, Mohini R: Effect of serum parathyroid hormone and bone marrow fibrosis on the response to erythropoietin in uremia. New Engl J Med. 1993, 328:171-175.

17. Brasil. Ministério da Saúde Protocolo Clínico e Diretrizes Terapêuticas Anemia em pacientes com insuficiência renal crônica - alfaepoetina Ministério da Saúde, Brasília (2010)

18. Slinin Y, Foley RN, Collins AJ: Calcium, phosphorus, parathyroid hormone, and cardiovascular disease in hemodialysis patients: the USRDS waves 1, 3, and 4 study. J Am Soc Nephrol. 2005, 16:1788-1793.

19. Palmer SC, Hayen A, Macaskill P, Pellegrini F, Craig JC, Elder GJ,et al.: Serum levels of phosphorus, parathyroid hormone, and calcium and risks of death and cardiovascular disease in individuals with CKD: a systematic review and meta-analysis. JAMA. 2011, 305:1119-1127.

20. Anees M, Ahmad S, Raja KM, Mushtaq M, Ibrahim M. Anemia and mineral bone disorders in patients with snd Stage renal disease on maintenance hemodialysis. Pak J Kidney Dis 2020;(11): 209-213.

21. Rizvi N, Tasleem F, Altaf U. Prevalence of mineral bone disease in dialysis patients. Pak J Kidney Dis 2020;(11):214-218.

22. Azeem SM, Haroon A, Alam I, Azeem S, Sultana M, Manssor K. Frequency of anemia in patients with increased level of parathyroid hormone among patients on maintenance hemodialysis. Professional Med J 2020; 27(6):1255-1258

23. Baradaran A, Nasri H. Intensification of anemia by secondary hyperparathyroidism in HD patients. Med J Islam Acad Sci. 2001;14:161-6.

24. Khan AM. Hyperparathyroidism as a Predictor of Erythropoietin Resistance in Chronic Kidney Disease. Int J Med Pharm. 2017;5:1-7.

25. Chutia H, Ruram AA, Bhattacharyya H, Boruah P, Nath C. Association of secondary hyperparathyroidism with hemoglobin level in patients with chronic kidney disease. J Lab Physicians. 2013;5:51-4.

26. Asif N, Rizwan M, Rehman A, Durrani N. Efficacy of Cholecalciferol in the management of secondary hyperparathyroidism in hemodialysis patients. Pak J Kidney Dis 2020;(11):203-208. 